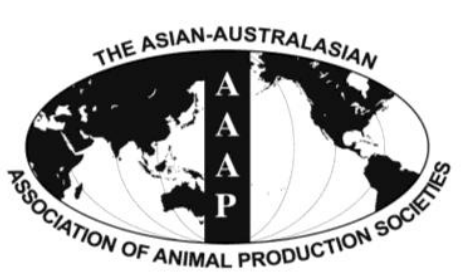

\title{
Aerobic Stability and Effects of Yeasts during Deterioration of Non-fermented and Fermented Total Mixed Ration with Different Moisture Levels
}

\author{
W. Hao, H. L. Wang, T. T. Ning, F. Y. Yang ${ }^{1}$, and C. C. Xu* \\ College of Engineering, China Agricultural University, Beijing 100083, China
}

\begin{abstract}
The present experiment evaluated the influence of moisture level and anaerobic fermentation on aerobic stability of total mixed ration (TMR). The dynamic changes in chemical composition and microbial population that occur after air exposure were examined, and the species of yeast associated with the deterioration process were also identified in both non-fermented and fermented TMR to deepen the understanding of aerobic deterioration. The moisture levels of TMR in this experiment were adjusted to $400 \mathrm{~g} / \mathrm{kg}$ (low moisture level, LML), $450 \mathrm{~g} / \mathrm{kg}$ (medium moisture level, MML), and $500 \mathrm{~g} / \mathrm{kg}$ (high moisture level, HML), and both nonfermented and 56-d-fermented TMR were subjected to air exposure to determine aerobic stability. Aerobic deterioration resulted in high losses of nutritional components and largely reduced dry matter digestibility. Non-fermented TMR deteriorated during $48 \mathrm{~h}$ of air exposure and the HML treatment was more aerobically unstable. On dry matter (DM) basis, yeast populations significantly increased from $10^{7}$ to $10^{10} \mathrm{cfu} / \mathrm{g}$ during air exposure, and Candida ethanolica was the predominant species during deterioration in non-fermented TMR. Fermented TMR exhibited considerable resistance to aerobic deterioration. Spoilage was only observed in the HML treatment and its yeast population increased dramatically to $10^{9} \mathrm{cfu} / \mathrm{g}$ DM when air exposure progressed to $30 \mathrm{~d}$. Zygosaccharomyces bailii was the sole yeast species isolated when spoilage occurred. These results confirmed that non-fermented and fermented TMR with a HML are more prone to spoilage, and fermented TMR has considerable resistance to aerobic deterioration. Yeasts can trigger aerobic deterioration in both non-fermented and fermented TMR. C. ethanolica may be involved in the spoilage of non-fermented TMR and the vigorous growth of Z. bailii can initiate aerobic deterioration in fermented TMR. (Key Words: Total Mixed Ration, Fermentation, Moisture Level, Aerobic Stability, Yeast)
\end{abstract}

\section{INTRODUCTION}

There is a common practice to preserve high-moisture by-products with dry feeds as fermented total mixed ration (TMR) in recent years, and this practice not only avoids the energy costs associated with drying but also improves the odors and flavors of the unpalatable by-products through anaerobic fermentation (Xu et al., 2007a,b; Xu et al., 2008; Cao et al., 2009). Fermented TMR results in highly enhanced aerobic stability (Nishino and Hattori, 2007; Wang and Nishino, 2008; Weinberg et al., 2011). This

\footnotetext{
* Corresponding Author: C. C. Xu. Tel: +86-10-62736480, Fax: +86-10-62737997, E-mail: xucc@cau.edu.cn

${ }^{1}$ College of Animal Science and Technology, China Agricultural University, Beijing 100094, China.

Submitted Oct. 29, 2014; Revised Dec. 28, 2014; Accepted Jan. 19, 2015
}

facilitates the transportation and flexible utilization of fermented TMR for a relatively long period without the occurrence of aerobic deterioration (Weinberg et al., 2011).

Multiple studies have investigated aerobic stability in fermented TMR. When anaerobic fermentation is prolonged to a month or longer, yeast counts can recede to levels below the limit of detection $\left(<10^{2}\right.$ colony forming units $(\mathrm{cfu}) / \mathrm{g}$ ), largely improving aerobic stability (Wang and Nishino, 2008a). It has been shown that silage with a high yeast population $\left(>10^{5} \mathrm{cfu} / \mathrm{g}\right)$ spoiled as soon as oxygen becomes available (McDonald et al., 1991). However, Nishino et al. (2004) reported that aerobic stability in fermented TMR was obtained even with more than $10^{6}$ cfu/g of yeast counted at silo opening. This suggests that the loss of aerobic stability has no significant correlation with yeast counts, but may be closely associated with the

Copyright $@ 2015$ by Asian-Australasian Journal of Animal Sciences This is an open-access article distributed under the terms of the Creative Commons Attribution Non-Commercial License (http://creativecommons.org/licenses/by-nc/3.0/) which permits unrestricted non-commercial use, distribution, and reproduction in any medium, provided the original work is properly cited. 
dominant yeast species present in fermented TMR. Candida and Hansenula species that are capable to metabolize lactic acid are considered to be the main cause of increased $\mathrm{pH}$ in silages, and Kluyveromyces marxianus was found in a fermented TMR that deteriorated during $7 \mathrm{~d}$ of air exposure (Wang and Nishino, 2013). Because the microbial flora varies depending on the specific ingredients of a TMR, it is difficult to generalize microbial dynamics during the phases of anaerobic fermentation and aerobic deterioration. However, there seems to be a narrow range of yeast genera involved in the initiation of aerobic deterioration, but this has not been well defined. For a better understanding of the mechanism of aerobic deterioration in non-fermented and fermented TMR, it is necessary to identify the dominant yeast species present during the period of air exposure. Characterization of yeasts at the genomic level has been enabled with the recent advances in molecular biology and analysis of the sequence divergence in yeast $26 \mathrm{~S}$ ribosomal DNA (rDNA), especially region D1/D2, has been widely applied to study the phylogeny of different yeast groups and is an important tool in yeast identification (Kurtzman and Robnett, 1998). The objectives of this study were to determine the effects of moisture level of non-fermented and fermented TMR on the dynamic changes in chemical composition and microbial population during aerobic deterioration, and to identify yeast species that are associated with aerobic deterioration in both non-fermented and fermented TMR.

\section{MATERIALS AND METHODS}

Total mixed ration preparation and anaerobic fermentation

As shown in Table 1, TMR was formulated with compound feed (Longde feed, Hebei, China), corn silage, Leymus Chinensis hay, alfalfa hay, cotton meal, wet brewers' grains, vitamin-mineral supplement (Longde feed, Hebei, China) and fat powder (Longde feed, Hebei, China), in a ratio of 37:22:16:11:5.2:4.5:3.5:0.8, respectively, on a dry matter (DM) basis. In this experiment, TMR was prepared in three independent batches and the moisture level of each batch was adjusted to $400 \mathrm{~g} / \mathrm{kg}$ (low moisture level, LML), $450 \mathrm{~g} / \mathrm{kg}$ (medium moisture level, MML), and $500 \mathrm{~g} / \mathrm{kg}$ (high moisture level, HML) to obtain the treatments of this experiment. Each treatment group was further divided into two portions. One portion (nonfermented TMR) was used to conduct aerobic stability study as described below immediately after TMR preparation. The other portion was first subjected to anaerobic fermentation by ensiling with approximately 40 $\mathrm{kg}$ TMR in a 60-L polyethylene barrel (triplicate barrels per each treatment) in a room with the temperature maintained at $27^{\circ} \mathrm{C}$ to $31^{\circ} \mathrm{C}$ and the fermented TMR was tested for
Table 1. Chemical composition of TMR ingredients

\begin{tabular}{lcccccc}
\hline \multirow{2}{*}{ Item } & \multicolumn{6}{c}{ Chemical composition (g/kg DM) } \\
\cline { 2 - 7 } & $\begin{array}{c}\mathrm{DM} \\
(\mathrm{g} / \mathrm{kg})\end{array}$ & $\mathrm{OM}^{1}$ & $\mathrm{CP}$ & $\mathrm{EE}$ & $\mathrm{NDF}$ & $\mathrm{ADF}$ \\
\hline Compound feed $^{1}$ & 866 & 925 & 176 & 36 & 157 & 74 \\
Corn silage $_{\text {Leymus chinensis hay }}$ & 353 & 931 & 82 & 35 & 558 & 287 \\
Alfalfa hay & 925 & 952 & 108 & 26 & 574 & 351 \\
Cotton meal & 915 & 960 & 172 & 19 & 475 & 308 \\
Brewers' grains & 285 & 936 & 368 & 9 & 387 & 259 \\
VMS & 245 & 952 & 259 & 90 & 574 & 207 \\
Fat powder & 908 & 831 & 125 & 71 & 150 & 63 \\
\hline
\end{tabular}

TMR, total mixed ration; DM, dry matter; OM, organic matter; $\mathrm{CP}$, crude protein; EE, ether extract; NDF, neutral detergent fiber; ADF, acid detergent fiber; VMS, vitamin-mineral supplement.

${ }^{1}$ Compound feed is a commercial product (Longde feed, Hebei, China); Vitamin-mineral supplement is a commercial product (Longde feed, China) containing $12 \mathrm{~g} / \mathrm{kg} \mathrm{Zn}, 10 \mathrm{~g} / \mathrm{kg} \mathrm{Mn}, 5 \mathrm{~g} / \mathrm{kg} \mathrm{Fe}, 2 \mathrm{~g} / \mathrm{kg} \mathrm{Cu}$, a minimum of 5,000 IU of vitamin A/g, $600 \mathrm{IU}$ of vitamin D/g; Fat powder is a commercial product (Longde feed, China) mainly containing fatty acids calcium, with fat content of approximately $840 \mathrm{~g} / \mathrm{kg}$.

aerobic stability after 56-d anaerobic fermentation in the same way as that for non-fermented TMR.

\section{Aerobic stability tests}

For the non-fermented TMR, triplicate 60-L polyethylene barrels were prepared for each treatment and approximately $15 \mathrm{~kg}$ TMR was added to the barrel without compaction. For fermented TMR, each silo was mixed thoroughly. Half (by weight) of the contents were discarded and the rest of the material was loosened, returned to the barrel, and kept uncovered during air exposure. The temperatures of ambience and materials were automatically monitored at $1-\mathrm{h}$ intervals by a thermocouple wire connected to a data logger (DT85 series2; Data Taker; Melbourne, Australia) and aerobic deterioration was considered to have occurred if the temperature difference between the materials and ambience reached $2^{\circ} \mathrm{C}$ (Nishino et al., 2004). Subsamples of non-fermented and fermented TMR were collected at $0,12,24,48,72,96,120,144,168$ $\mathrm{h}$ and $0,7,14,21$, and $30 \mathrm{~d}$ after stating the aerobic stability tests.

\section{Chemical analyses and microbial enumeration}

Samples were dried in a forced draught oven at $60^{\circ} \mathrm{C}$ for $48 \mathrm{~h}$ and ground with a Wiley mill to pass through a $1-\mathrm{mm}$ screen. The DM, crude protein (CP), ether extract, and organic matter were analyzed according to methods 934.01, 976.05, 920.39, and 942.05, respectively, of the Association of Official Analytic Chemists (AOAC, 1990). Acid detergent fiber, neutral detergent fiber, water soluble carbohydrate (WSC), and in vitro DM digestibility (IVDMD) were measured according to the method of $\mathrm{Xu}$ et al. (2011). Fermentation quality was determined by 
measuring fermentation products in cold water extracts. Material (10 g) was randomly collected and homogenized with $90 \mathrm{~mL}$ of autoclaved sterilized distilled water. $\mathrm{pH}$ was measured with Mettler Toledo S20 pH meter (Mettler Toledo, Zurich, Switzerland), and ammonia nitrogen $\left(\mathrm{NH}_{3}-\right.$ $\mathrm{N})$ was determined by steam distillation of the filtrates $(\mathrm{Xu}$ et al., 2007a). The concentrations of organic acids were measured by high performance liquid chromatography (Jasco, Tokyo, Japan), and the analytical conditions were as follows: column, ShodexRspak KC-811S-DVB gel column $30 \times 8 \mathrm{~mm}$; oven temperature, $50^{\circ} \mathrm{C}$; mobile phase, $3 \mathrm{mmol}$ $\mathrm{HClO}_{4}, 1.0 \mathrm{~mL} / \mathrm{min}$; detector, SPD-M10QVp.

Populations of microorganisms were counted according to the method of $\mathrm{Xu}$ et al. (2008). Samples (10 g) were blended with $90 \mathrm{~mL}$ sterilized distilled water, and were $10^{-1}$ to $10^{-9}$ serially diluted. Colonies were counted from the plates at appropriate dilutions and the cfu number was expressed per gram of DM. Lactic acid bacteria (LAB) were measured by a plate count on deMan, Rogosa, and Sharpe agar (Difco Laboratories, Detroit, MI, USA) after incubation at $37^{\circ} \mathrm{C}$ for $48 \mathrm{~h}$ under anaerobic conditions. Aerobic bacteria were counted on nutrient agar medium (Nissui-Seiyaku Ltd., Tokyo, Japan) incubated for $48 \mathrm{~h}$ at $30^{\circ} \mathrm{C}$ under aerobic conditions. Yeasts were counted on potato dextrose agar (Nissui-Seiyaku Ltd., Japan) acidified with sterilized tartaric acid solution to $\mathrm{pH} 3.5$, after incubation for $24 \mathrm{~h}$ at $30^{\circ} \mathrm{C}$, and were distinguished from molds based on colony appearance and cell morphology. Each yeast colony was purified by streaking on yeast extract peptone dextrose agar (Difco Laboratories; USA), and the purified strains were stored at $-80^{\circ} \mathrm{C}$ with $10 \mathrm{~g} / \mathrm{L}$ glycerin for further analysis.

\section{Extraction of genomic DNA and identification of yeasts}

A total of 93 and 13 strains of yeasts were picked from the non-fermented and fermented TMR during the process of aerobic deterioration, respectively. Genomic DNA of yeast was extracted according to the method described by Makimura et al. (1994) and stored at $-20^{\circ} \mathrm{C}$ until use. Polymerase chain reaction (PCR) was carried out to amplify the D1/D2 region of 26S rDNA sequences of yeasts using primers NL1 (5'-GCA TAT CAA TAA GCG GAG GAA AAG-3') and NL4 (5'-GGT CCG TGT TTC AAG ACG G$\left.3^{\prime}\right)$. The PCR mixture contained $5.0 \mu \mathrm{L} 10 \times$ PCR buffer (with $\mathrm{Mg}^{2+}$ ), $4.0 \mu \mathrm{L}$ dNTP $(2 \mu \mathrm{M}), 0.5 \mu \mathrm{L}$ Taq polymerase (5 U/ $\mu \mathrm{L}), 2.0 \mu \mathrm{L}$ DNA template, $0.4 \mu \mathrm{L}$ each of primer $(2$ $\mathrm{mM}$ ), and double-distilled water to a total volume of $50 \mu \mathrm{L}$. The PCR was conducted in a PCR thermal cycler (TP-600; Takara Bio Inc., Shiga, Japan) with the following protocol: an initial denaturation at $95^{\circ} \mathrm{C}$ for $5 \mathrm{~min} ; 36$ cycles of denaturation at $94^{\circ} \mathrm{C}$ for $1 \mathrm{~min}$, primer annealing at $52^{\circ} \mathrm{C}$ for $1 \mathrm{~min}$, and elongation at $72^{\circ} \mathrm{C}$ for $80 \mathrm{~s}$, and a final elongation at $72^{\circ} \mathrm{C}$ for $8 \mathrm{~min}$. After purification, the PCR products were analyzed on an ABI 377 DNA Analyzer (Applied Biosystems, Foster City, CA, USA). Sequence searches were performed against the GenBank data library using BLAST. Sequence information of type strains was imported into CLUSTER W software for assembly and alignment, and the sequences of isolates were compared to the sequences of type strains. Nucleotide substitution rates were calculated (Kimura and Ohta, 1972), and a phylogenetic tree was constructed by the neighbor-joining method (Saitou and Nei, 1987). The topology of the tree was evaluated by bootstrap analysis of the sequence data with CLUSTER W based on 1,000 random resamplings (Thompson et al., 1994). The nucleotide sequences for the D1/D2 region of yeast 26S rDNA described here were deposited in GenBank under the following accession numbers: KM062151 for Y1, KM062152 for Y2, KM062153 for Y3, KM062154 for Y4, KM062155 for Y5, KM062156 for Y6, KM062157 for Y7, KM062158 for Y8, KM062159 for Y9, and KM062160 for Y10.

\section{Statistical analysis}

The study was carried out in a complete randomized design. The data on the chemical composition and microbial population in 56-d-fermented TMR were analyzed by oneway analysis of variance to evaluate the effects of moisture level. The significant differences between the means were identified from the p-values and the effects were considered significant at $\mathrm{p}<0.05$. The Tukey's test was used to interpret differences $(p<0.05)$ among the mean values.

The data on the chemical composition during air exposure in non-fermented and fermented TMR were analyzed by using the general linear model procedure, and the fixed effects were moisture level, air exposure time, and the interaction between moisture level and exposure time:

$$
Y_{i j k}=\mu+M L_{i}+E T_{j}+(M L \times E T)_{i j}+\varepsilon_{i j k}
$$

Where $Y_{i j k}=$ dependent variable; $\mu=$ overall mean; $M L_{i}$ = effect of moisture level; $E T_{j}=$ effect of exposure time; $(M L \times E T)_{i j}=$ interaction effect between moisture level and exposure time; and $\varepsilon_{i j k}=$ residual error. The differences between means were assessed by Tukey's multiple comparison test, and the effects were considered significant when p-values were less than 0.05. All analyses were performed using SAS 9.0 (SAS Institute Inc., Cary, NC, USA) for Windows.

\section{RESULTS}

The chemical composition and microbial population of non-fermented and fermented TMR are shown in Table 2. Initial moisture levels of non-fermented TMR were close to 
Table 2. Chemical composition and microbial population of non-fermented and 56-d-fermented TMR

\begin{tabular}{|c|c|c|c|c|c|c|c|c|}
\hline \multirow{2}{*}{ Item } & \multicolumn{3}{|c|}{$\mathrm{TMR}^{1}$} & \multicolumn{5}{|c|}{ 56-d-fermented TMR ${ }^{1}$} \\
\hline & LML & MML & HML & LML & MML & HML & $\mathrm{SEM}^{2}$ & p-value \\
\hline \multicolumn{9}{|c|}{ Chemical composition (g/kg DM) } \\
\hline $\mathrm{DM}(\mathrm{g} / \mathrm{kg})$ & 625 & 568 & 517 & $609^{\mathrm{a}}$ & $559^{\mathrm{b}}$ & $504^{\mathrm{c}}$ & 7.80 & $<0.001$ \\
\hline $\mathrm{CP}$ & 154 & 154 & 152 & 151 & 154 & 154 & 2.28 & 0.372 \\
\hline WSC & 65 & 62 & 65 & 45 & 46 & 49 & 2.02 & 0.184 \\
\hline $\mathrm{NDF}$ & 376 & 372 & 377 & 390 & 398 & 394 & 7.94 & 0.625 \\
\hline $\mathrm{ADF}$ & 205 & 207 & 204 & 228 & 238 & 233 & 7.75 & 0.472 \\
\hline \multicolumn{9}{|c|}{ Fermentation quality (g/kg DM) } \\
\hline $\mathrm{pH}$ & 5.22 & 5.23 & 5.11 & $4.18^{\mathrm{a}}$ & $4.16^{\mathrm{ab}}$ & $4.15^{\mathrm{b}}$ & 0.01 & 0.023 \\
\hline Lactic acid & - & - & - & $76.0^{\mathrm{c}}$ & $83.7^{\mathrm{b}}$ & $85.1^{\mathrm{a}}$ & 0.42 & $<0.001$ \\
\hline Acetic acid & - & - & - & $17.9^{\mathrm{b}}$ & $19.1^{\mathrm{ab}}$ & $20.1^{\mathrm{a}}$ & 0.54 & 0.011 \\
\hline Propionic acid & - & - & - & 2.5 & 2.8 & 2.9 & 0.28 & 0.397 \\
\hline Butyric acid & - & - & - & ND & ND & ND & - & - \\
\hline $\mathrm{NH}_{3}-\mathrm{N}(\mathrm{g} / \mathrm{kg} \mathrm{TN})$ & - & - & - & $43.7^{\mathrm{c}}$ & $53.9^{\mathrm{b}}$ & $58.3^{\mathrm{a}}$ & 1.18 & $<0.001$ \\
\hline \multicolumn{9}{|c|}{ Microbial population $\left(\log _{10} \mathrm{cfu} / \mathrm{g} \mathrm{DM}\right)$} \\
\hline Lactic acid bacteria & 7.3 & 7.4 & 7.4 & 6.2 & 5.7 & 6.1 & 0.16 & 0.057 \\
\hline Yeasts & 6.1 & 6.2 & 6.3 & ND & ND & ND & - & - \\
\hline Aerobic bacteria & 6.8 & 6.7 & 6.8 & $6.3^{\mathrm{a}}$ & $5.9^{\mathrm{b}}$ & $6.1^{\mathrm{ab}}$ & 0.13 & 0.031 \\
\hline
\end{tabular}

TMR, total mixed ration; LML, low moisture level; MML, medium moisture level; HML, high moisture level; SEM, standard error of the mean; $p$, standard probability; DM, dry matter; CP, crude protein; WSC, water soluble carbohydrate; NDF, neutral detergent fiber; ADF, acid detergent fiber; TN, total nitrogen; ND, not detected.

${ }^{1}$ Treatments of TMR and 56-d-fermented TMR: LML, moisture level of $400 \mathrm{~g} / \mathrm{kg}$; MML, moisture level of $450 \mathrm{~g} / \mathrm{kg}$; HML, moisture level of $500 \mathrm{~g} / \mathrm{kg}$.

${ }^{2} \mathrm{n}=3$.

${ }^{\mathrm{a}-\mathrm{c}}$ Means within a row with different superscripts differ $(\mathrm{p}<0.05)$.

the expected values, ranging from $375 \mathrm{~g} / \mathrm{kg}$ to $483 \mathrm{~g} / \mathrm{kg}$, and the WSC concentrations were above $60 \mathrm{~g} / \mathrm{kg} \mathrm{DM}$ in all treatments. On a DM basis, population sizes of LAB and yeasts were approximately $10^{7} \mathrm{cfu} / \mathrm{g}$ and $10^{6} \mathrm{cfu} / \mathrm{g}$, respectively. After $56 \mathrm{~d}$ of anaerobic fermentation, moisture level affected the fermentation quality significantly. $\mathrm{pH}$ decreased to below 4.2 in all treatments, and fermented TMR with higher moisture level obtained higher concentrations of lactic and acetic acids $(\mathrm{p}<0.001 ; \mathrm{p}=$ 0.011). The LAB populations decreased to approximately
$10^{6} \mathrm{cfu} / \mathrm{g}$ DM and yeast counts receded to levels below the detection limit, irrespective of the moisture contents.

Dynamic changes of temperature were monitored in non-fermented and 56-d-fermented TMR during air exposure (Figure 1). For non-fermented TMR, heating was found in all treatments during air exposure. The temperature of the HML treatment increased much more promptly than in the other two treatments. Deterioration occurred in the HML, MML, and LML treatments at $7 \mathrm{~h}, 18 \mathrm{~h}$, and $30 \mathrm{~h}$, respectively, indicated by the temperatures exceeding the
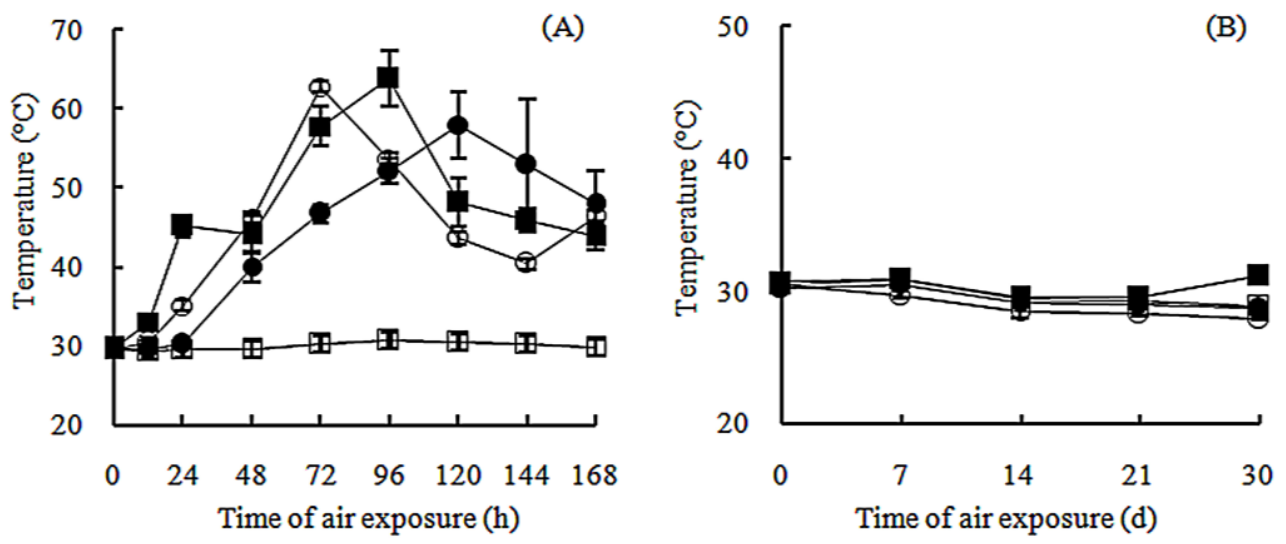

Figure 1. Dynamic changes of temperatures during air exposure of non-fermented (A) and 56-d-fermented total mixed ration, (B) with moisture levels of $400 \mathrm{~g} / \mathrm{kg}(\bullet), 450 \mathrm{~g} / \mathrm{kg}(\mathrm{O})$, and $500 \mathrm{~g} / \mathrm{kg}(\bullet)$. Ambient temperatures were marked by $\square$. Points indicate mean values of triplicate samples, with standard deviations represented by vertical bars. 
ambient temperature by approximately $2{ }^{\circ} \mathrm{C}$. Fermented TMR exhibited considerable resistance to spoilage. Aerobic deterioration was only found in the HML treatment at $30 \mathrm{~d}$, but no heating was observed in the LML and MML treatments throughout the duration of air exposure.

The influence of moisture level and exposure time on the chemical composition and IVDMD were investigated in non-fermented and 56-d-fermented TMR (Tables 3 and 4). For non-fermented TMR, a higher moisture level led to an increased concentration of WSC $(\mathrm{p}<0.001)$, whereas the moisture content did not influence the CP concentration in non-fermented TMR $(p=0.197)$. The process of aerobic deterioration significantly increased the DM $(\mathrm{p}<0.001)$ and CP concentrations $(\mathrm{p}=0.015)$, whereas the WSC concentration decreased in the first $24 \mathrm{~h}$ and then remarkably increased in the later phase of aerobic deterioration $(\mathrm{p}<0.001)$. The IVDMD significantly decreased $(p<0.001)$ and DM loss was largely accelerated with the extended exposure time $(\mathrm{p}<0.001)$. For fermented TMR, the CP concentration significantly increased $(\mathrm{p}<0.001)$ while the WSC concentration largely decreased

Table 3. Effects of moisture level and exposure time on chemical composition and in vitro DM digestibility of non-fermented TMR

\begin{tabular}{|c|c|c|c|c|c|}
\hline \multirow[t]{2}{*}{ Items } & \multicolumn{3}{|c|}{$\begin{array}{l}\text { Chemical composition } \\
(\mathrm{g} / \mathrm{kg} \mathrm{DM})\end{array}$} & \multicolumn{2}{|c|}{$\mathrm{g} / \mathrm{kg} \mathrm{DM}$} \\
\hline & $\overline{\mathrm{DM}(\mathrm{g} / \mathrm{kg})}$ & $\mathrm{CP}$ & WSC & DM loss & IVDMD \\
\hline \multicolumn{6}{|c|}{ Moisture level (ML) $^{1}$} \\
\hline LML & $686^{\mathrm{a}}$ & 160 & $76^{\mathrm{c}}$ & $55^{\mathrm{c}}$ & 662 \\
\hline MML & $651^{\mathrm{b}}$ & 157 & $83^{\mathrm{b}}$ & $85^{b}$ & 650 \\
\hline HML & $606^{\mathrm{c}}$ & 158 & $90^{\mathrm{a}}$ & $124^{\mathrm{a}}$ & 660 \\
\hline SEM & 6.66 & 1.98 & 2.37 & 8.52 & 7.42 \\
\hline \multicolumn{6}{|c|}{ Exposure time (ET, h) } \\
\hline 0 & $570^{\mathrm{f}}$ & $153^{\mathrm{c}}$ & $64^{\mathrm{d}}$ & $0^{\mathrm{e}}$ & $702^{\mathrm{a}}$ \\
\hline 12 & $571^{\mathrm{f}}$ & $154^{\mathrm{c}}$ & $54^{\mathrm{e}}$ & $4^{\mathrm{e}}$ & $687^{\mathrm{a}}$ \\
\hline 24 & $582^{\mathrm{ef}}$ & $154^{\mathrm{c}}$ & $59^{\mathrm{de}}$ & $6^{\mathrm{e}}$ & $683^{a b}$ \\
\hline 48 & $599^{\mathrm{e}}$ & $159^{\mathrm{abc}}$ & $83^{c}$ & $52^{\mathrm{d}}$ & $660^{\mathrm{bc}}$ \\
\hline 72 & $623^{\mathrm{d}}$ & $165^{\mathrm{ab}}$ & $98^{\mathrm{ab}}$ & $109^{c}$ & $634^{\mathrm{cd}}$ \\
\hline 96 & $673^{c}$ & $159^{\mathrm{abc}}$ & $95^{\mathrm{ab}}$ & $117^{\mathrm{bc}}$ & $647^{\mathrm{cd}}$ \\
\hline 120 & $720^{\mathrm{b}}$ & $159^{\mathrm{abc}}$ & $103^{\mathrm{a}}$ & $142^{\mathrm{b}}$ & $643^{\mathrm{cd}}$ \\
\hline 144 & $726^{\mathrm{b}}$ & $158^{\mathrm{bc}}$ & $93^{\mathrm{b}}$ & $179^{\mathrm{a}}$ & $626^{\mathrm{d}}$ \\
\hline 168 & $765^{\mathrm{a}}$ & $165^{\mathrm{a}}$ & $98^{\mathrm{ab}}$ & $177^{\mathrm{a}}$ & $632^{\mathrm{d}}$ \\
\hline SEM & 11.54 & 3.43 & 4.11 & 14.75 & 12.86 \\
\hline \multicolumn{6}{|l|}{ p-value } \\
\hline ML & $<0.001$ & 0.197 & $<0.001$ & $<0.001$ & 0.227 \\
\hline ET & $<0.001$ & 0.015 & $<0.001$ & $<0.001$ & $<0.001$ \\
\hline ML×ET & 0.093 & 0.553 & $<0.001$ & 0.001 & 0.106 \\
\hline
\end{tabular}

DM, dry matter; TMR, total mixed ration; CP, crude protein; WSC, water soluble carbohydrate; IVDMD, in vitro DM digestibility; LML, low moisture level; MML, medium moisture level; HML, high moisture level; SEM, standard error of the mean; $p$, standard probability.

${ }^{1}$ Treatments of non-fermented TMR: LML, moisture level of $400 \mathrm{~g} / \mathrm{kg}$; MML, moisture level of $450 \mathrm{~g} / \mathrm{kg}$; HML, moisture level of $500 \mathrm{~g} / \mathrm{kg} ; \mathrm{n}=$ 3.

${ }^{a-f}$ Means within a column with different superscripts differ $(\mathrm{p}<0.05)$.
Table 4. Effects of moisture level and exposure time on chemical composition and in vitro DM digestibility of 56-d-fermented TMR

\begin{tabular}{|c|c|c|c|c|c|}
\hline \multirow[t]{2}{*}{ Items } & \multicolumn{3}{|c|}{$\begin{array}{c}\text { Chemical composition } \\
\text { (g/kg DM) }\end{array}$} & \multicolumn{2}{|c|}{$\mathrm{g} / \mathrm{kg} \mathrm{DM}$} \\
\hline & $\mathrm{DM}(\mathrm{g} / \mathrm{kg})$ & $\mathrm{CP}$ & WSC & DM loss & IVDMD \\
\hline \multicolumn{6}{|c|}{$\overline{\text { Moisture level (ML) }}{ }^{1}$} \\
\hline LML & $633^{\mathrm{a}}$ & $149^{\mathrm{c}}$ & $35^{\mathrm{c}}$ & $0.0^{\mathrm{b}}$ & 670 \\
\hline MML & $573^{\mathrm{b}}$ & $155^{\mathrm{b}}$ & $40^{\mathrm{b}}$ & $2.0^{\mathrm{b}}$ & 666 \\
\hline HML & $518^{\mathrm{c}}$ & $160^{\mathrm{a}}$ & $44^{\mathrm{a}}$ & $6.2^{\mathrm{a}}$ & 671 \\
\hline SEM & 3.80 & 0.92 & 1.27 & 1.61 & 13.43 \\
\hline \multicolumn{6}{|c|}{ Exposure time (ET, d) } \\
\hline 0 & $548^{\mathrm{d}}$ & $153^{\mathrm{bc}}$ & $47^{\mathrm{a}}$ & $0.0^{\mathrm{b}}$ & 683 \\
\hline 7 & $566^{\mathrm{c}}$ & $151^{\mathrm{c}}$ & $41^{\mathrm{b}}$ & $0.2^{\mathrm{b}}$ & 654 \\
\hline 14 & $573^{\mathrm{bc}}$ & $152^{\mathrm{c}}$ & $40^{\mathrm{bc}}$ & $0.9^{\mathrm{b}}$ & 677 \\
\hline 21 & $581^{\mathrm{ab}}$ & $156^{\mathrm{b}}$ & $38^{\mathrm{bc}}$ & $0.5^{\mathrm{b}}$ & 669 \\
\hline 30 & $591^{\mathrm{a}}$ & $161^{\mathrm{a}}$ & $35^{\mathrm{c}}$ & $12.1^{\mathrm{a}}$ & 662 \\
\hline SEM & 4.90 & 1.19 & 1.67 & 2.12 & 17.34 \\
\hline \multicolumn{6}{|l|}{$\mathrm{p}$-value } \\
\hline ML & $<0.001$ & $<0.001$ & $<0.001$ & 0.006 & 0.919 \\
\hline ET & $<0.001$ & $<0.001$ & $<0.001$ & $<0.001$ & 0.488 \\
\hline ML $\times E T$ & 0.974 & 0.014 & 0.700 & 0.002 & 0.337 \\
\hline
\end{tabular}

DM, dry matter; TMR, total mixed ration; CP, crude protein; WSC, water soluble carbohydrate; IVDMD, in vitro DM digestibility; LML, low moisture level; MML, medium moisture level; HML, high moisture level; SEM, standard error of the mean; $p$, standard probability.

${ }^{1}$ Treatments of fermented TMR: LML, moisture level of $400 \mathrm{~g} / \mathrm{kg}$; MML, moisture level of $450 \mathrm{~g} / \mathrm{kg}$; HML, moisture level of $500 \mathrm{~g} / \mathrm{kg} ; \mathrm{n}=3$.

${ }^{a-d}$ Means within a column with different superscripts differ $(\mathrm{p}<0.05)$.

during air exposure $(\mathrm{p}<0.001)$. The extent of DM loss significantly increased when deterioration occurred to the HML treatment at $30 \mathrm{~d}(\mathrm{p}<0.001)$. The IVDMD was not affected by either moisture level $(\mathrm{p}=0.919)$ or exposure time $(\mathrm{p}=0.488)$.

Dynamic changes of fermentation products that occurred in non-fermented and 56-d-fermented TMR were characterized after air exposure (Figure 2). For nonfermented TMR, lactic acid concentrations initially remained relatively stable, then increased, and finally decreased, peaking at $72 \mathrm{~h}, 48 \mathrm{~h}$, and $24 \mathrm{~h}$ in the LML, MML, and HML treatments, respectively. The concentrations of acetic acid were significantly reduced after $24 \mathrm{~h}$ and $12 \mathrm{~h}$ in the LML and MML treatments, respectively, whereas the concentration in the HML treatment decreased rapidly at the very beginning of air exposure. For 56-d-fermented TMR, the lactic acid concentration in the HML treatment showed a trend from a rise to a decline, and acetic acid concentration significantly decreased to approximately $10 \mathrm{~g} / \mathrm{kg}$ DM when aerobic deterioration occurred at $30 \mathrm{~d}$. In the LML and MML treatments, the concentrations of lactic and acetic acids remained relatively stable throughout the duration of air exposure. Aerobic deterioration induced large increases in $\mathrm{pH}$ values in both the non-fermented and fermented TMR. 

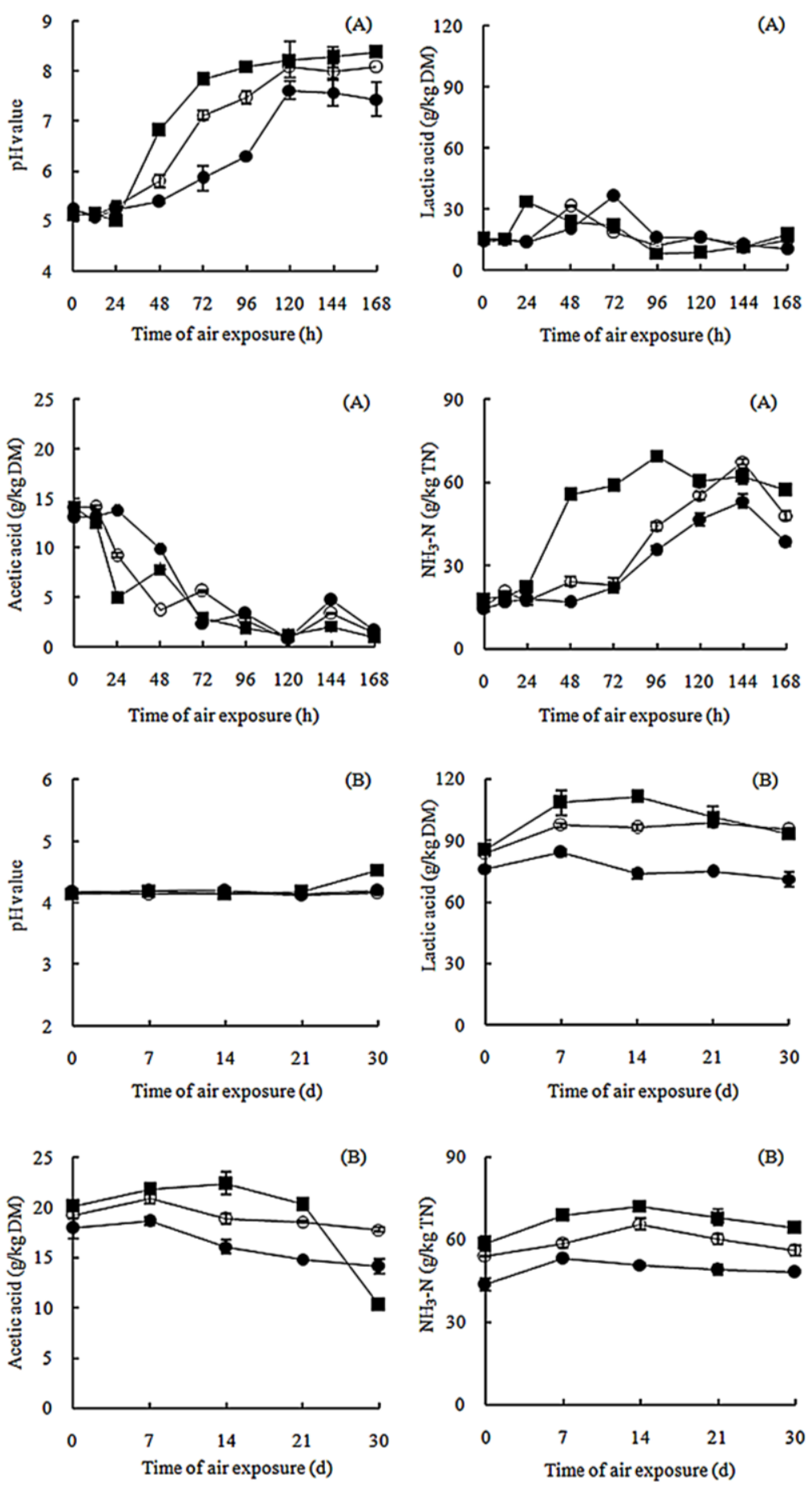

Figure 2. Dynamic changes of fermentation products of non-fermented (A) and 56-d-fermented total mixed ration, (B) with moisture levels of $400 \mathrm{~g} / \mathrm{kg}(\bullet), 450 \mathrm{~g} / \mathrm{kg}(\circ)$, and $500 \mathrm{~g} / \mathrm{kg}(\bullet)$ during air exposure. Points indicate mean values of triplicate samples, with standard deviations represented by vertical bars. $\mathrm{NH}_{3}-\mathrm{N}$, ammonia nitrogen; $\mathrm{TN}$, total nitrogen.

The changing processes in the composition of the microbial populations in non-fermented and 56-d-fermented TMR were observed during air exposure (Figure 3). For non-fermented TMR, high populations of LAB $\left(\sim 10^{7} \mathrm{cfu} / \mathrm{g}\right.$ $\mathrm{DM}$ to $\left.10^{10} \mathrm{cfu} / \mathrm{g} \mathrm{DM}\right)$ were sustained during air exposure and the LAB populations initially increased and subsequently decreased during the exposure period. Yeast counts increased to above $10^{9} \mathrm{cfu} / \mathrm{g}$ DM during deterioration and reached the maximum at $96 \mathrm{~h}, 48 \mathrm{~h}$, and $24 \mathrm{~h}$ in the LML, MML, and HML treatments, respectively. The numbers of aerobic bacteria increased rapidly and subsequently were maintained at a level of approximately $10^{10} \mathrm{cfu} / \mathrm{g}$ DM in all treatments. For fermented TMR, significant increases in the populations of LAB and aerobic 

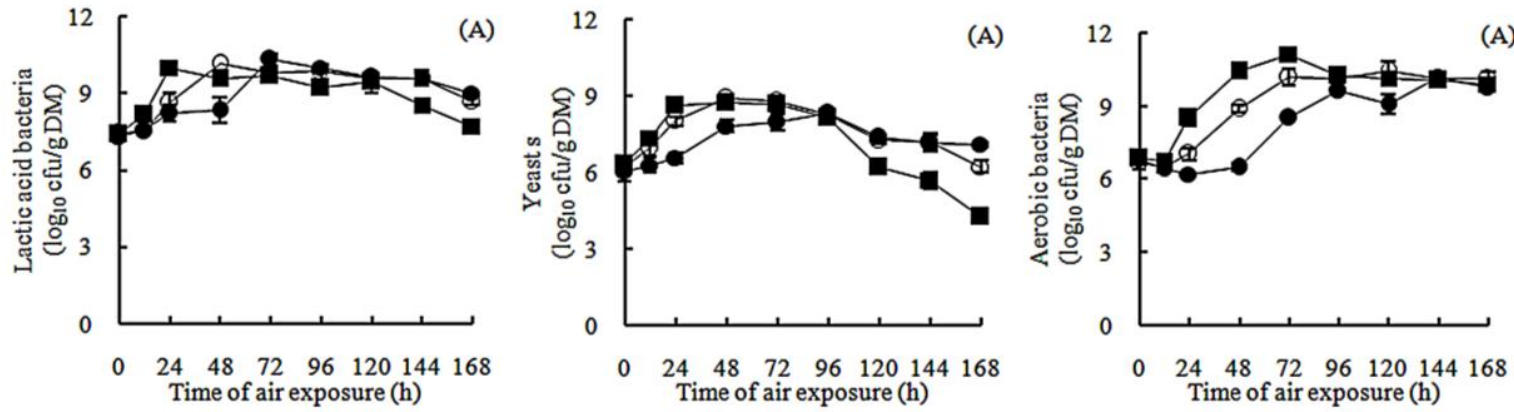

(A)
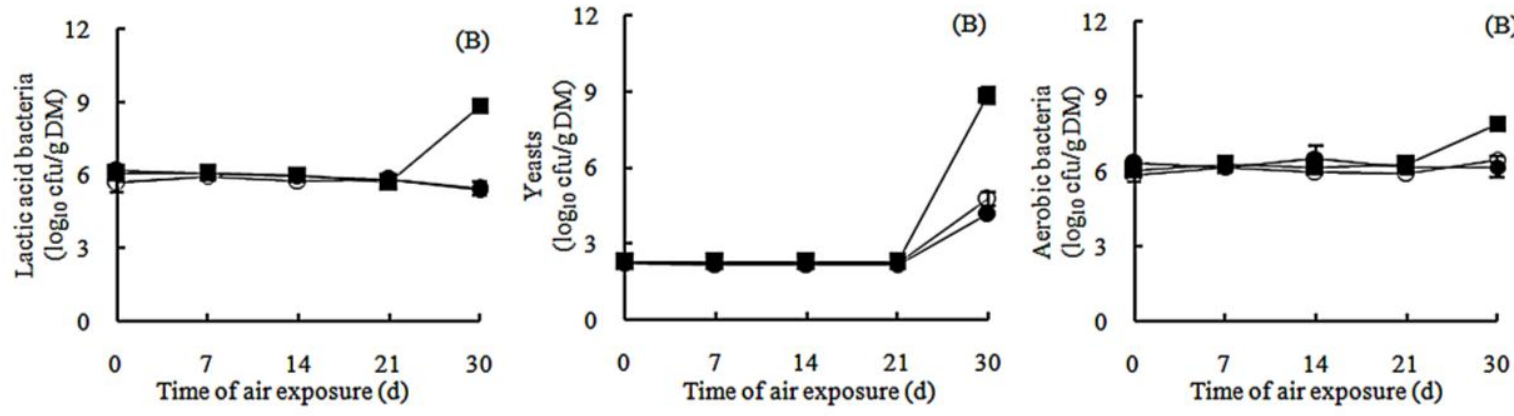

Figure 3. Dynamic changes of microbial populations of non-fermented (A) and 56-d-fermented total mixed ration, (B) with moisture levels of $400 \mathrm{~g} / \mathrm{kg}(\bullet), 450 \mathrm{~g} / \mathrm{kg}(\circ)$, and $500 \mathrm{~g} / \mathrm{kg}(\bullet)$ during air exposure. Points indicate mean values of triplicate samples, with standard deviations represented by vertical bars.

bacteria were observed in the HML treatment during air exposure, and the yeast count dramatically increased to $10^{9}$ cfu/g DM when aerobic deterioration occurred. The microbial populations in the other two treatments remained relatively stable, and the yeast counts increased to $10^{4} \mathrm{cfu} / \mathrm{g}$ $\mathrm{DM}$ and $10^{5} \mathrm{cfu} / \mathrm{g} \mathrm{DM}$ in LML and MML treatments, respectively, when air exposure terminated at $30 \mathrm{~d}$.

A total of 93 and 13 yeast strains were isolated from non-fermented and 56-d-fermented TMR during aerobic deterioration, respectively. The isolated yeast strains were identified as eight species, showing more than $99 \%$ similarity with the D1/D2 region of 26S rDNA gene sequences of the corresponding type strains (Figure 4).

Table 5 lists the dominant yeast species observed during the initial phase of aerobic deterioration in non-fermented TMR. Kluyveromyces marxianus, Candida rugosa, Candida ethanolica, Pichia manshurica, and Pichia membranifaciens were discovered in non-fermented TMR before being subjected to air exposure. C. ethanolica and $C$. rugosa were the most frequently observed yeast species during aerobic deterioration. The species $C$. ethanolica occurred in a larger population at the beginning of aerobic

Table 5. Dominant yeast species isolated from the initial $72 \mathrm{~h}$ of aerobically exposed non-fermented TMR

\begin{tabular}{|c|c|c|c|c|c|c|c|c|c|c|c|c|c|c|c|}
\hline \multirow{3}{*}{ No. } & \multirow{3}{*}{ Type strains $^{1}$} & \multirow{3}{*}{$\begin{array}{l}\text { Similarity } \\
\%\end{array}$} & \multicolumn{13}{|c|}{ Proportion of isolated species ${ }^{2}$} \\
\hline & & & \multirow{2}{*}{$0 \mathrm{~h}$} & \multicolumn{4}{|c|}{ LML } & \multicolumn{4}{|c|}{ MML } & \multicolumn{4}{|c|}{ HML } \\
\hline & & & & $12 \mathrm{~h}$ & $24 \mathrm{~h}$ & $48 \mathrm{~h}$ & $72 \mathrm{~h}$ & $12 \mathrm{~h}$ & $24 \mathrm{~h}$ & $48 \mathrm{~h}$ & $72 \mathrm{~h}$ & $12 \mathrm{~h}$ & $24 \mathrm{~h}$ & $48 \mathrm{~h}$ & $72 \mathrm{~h}$ \\
\hline$\overline{\mathrm{Y} 1}$ & $\begin{array}{l}\text { Kluyveromycesmarxianus } \\
\text { NRRL Y-8281 } / \text { U94924 }\end{array}$ & 100 & 0.11 & ND & ND & ND & ND & ND & ND & ND & ND & ND & ND & ND & ND \\
\hline $\mathrm{Y} 2 / \mathrm{Y} 3$ & $\begin{array}{l}\text { Candida rugosa } \\
\text { NRRL Y-95 }{ }^{\mathrm{T}} / \mathrm{U} 45727\end{array}$ & $99.59-100$ & 0.44 & 0.50 & ND & ND & 0.5 & 0.50 & 0.25 & 0.50 & 0.75 & 0.33 & 0.50 & 1.00 & 0.75 \\
\hline Y4 & $\begin{array}{l}\text { Pichiamanshurica } \\
\text { NRRL Y-17349 / U75738 }\end{array}$ & 100 & 0.11 & ND & ND & 0.60 & 0.5 & ND & ND & ND & ND & 0.17 & ND & ND & ND \\
\hline Y5-Y7 & $\begin{array}{l}\text { Candida ethanolica } \\
\text { NRRL Y-12615 / U71073 }\end{array}$ & $99.46-100$ & 0.22 & 0.25 & 0.75 & 0.40 & ND & 0.50 & 0.50 & 0.50 & 0.25 & 0.50 & 0.25 & ND & ND \\
\hline Y8 & $\begin{array}{l}\text { Pichiamembranifaciens NRRL } \\
\text { Y-2026 / U75725 }\end{array}$ & 99.47 & 0.11 & 0.25 & ND & ND & ND & ND & ND & ND & ND & ND & ND & ND & ND \\
\hline Y9 & $\begin{array}{l}\text { Pichiakudriavzevii } \\
\text { NRRL Y-5396 }^{\mathrm{T}} \text { / U76347 }\end{array}$ & 100 & ND & ND & 0.25 & ND & ND & ND & 0.25 & ND & ND & ND & 0.25 & ND & 0.25 \\
\hline
\end{tabular}

TMR, total mixed ration; LML, low moisture level; MML, medium moisture level; HML, high moisture level; ND, not detected.

${ }^{1}$ The GenBank accession no. of each type strain D1/D2 region 26S rDNA sequence was shown behind the type strain.

${ }^{2}$ Treatments of non-fermented TMR: LML, moisture level of $400 \mathrm{~g} / \mathrm{kg}$, MML, moisture level of $450 \mathrm{~g} / \mathrm{kg}$, HML, moisture level of $500 \mathrm{~g} / \mathrm{kg}$. 
Table 6. Dominant yeast species isolated from the initial $30 \mathrm{~d}$ of aerobically exposed 56-d-fermented TMR

\begin{tabular}{|c|c|c|c|c|c|c|c|c|}
\hline \multirow{3}{*}{ No. } & \multirow{3}{*}{ Type strains ${ }^{1}$} & \multirow{3}{*}{ Similarity $\%$} & \multicolumn{6}{|c|}{ Proportion of isolated species ${ }^{2}$} \\
\hline & & & \multicolumn{2}{|c|}{ LML } & \multicolumn{2}{|c|}{ MML } & \multicolumn{2}{|c|}{ HML } \\
\hline & & & $0 \mathrm{~d}$ & $30 \mathrm{~d}$ & $0 \mathrm{~d}$ & $30 \mathrm{~d}$ & $0 \mathrm{~d}$ & $30 \mathrm{~d}$ \\
\hline Y10 & $\begin{array}{l}\text { Zygosaccharomyces bailii } \\
\text { NRRL Y-2227T / U72161 }\end{array}$ & 99.32 & $\mathrm{ND}^{3}$ & 1.0 & ND & 1.0 & ND & 1.0 \\
\hline
\end{tabular}

TMR, total mixed ration; LML, low moisture level; MML, medium moisture level; HML, high moisture level; ND, not detected.

${ }^{1}$ The GenBank accession no. of each type strain D1/D2 region 26S rDNA sequence was shown behind the type strain.

${ }^{2}$ Treatments of fermented TMR: LML, moisture level of $400 \mathrm{~g} / \mathrm{kg}$, MML, moisture level of $450 \mathrm{~g} / \mathrm{kg}$; HML, moisture level of $500 \mathrm{~g} / \mathrm{kg}$.

spoilage in all treatments, whereas $C$. rugosa was not isolated in the LML treatment at $24 \mathrm{~h}$ and $48 \mathrm{~h}$. The species $P$. manshurica dominated in the HML and LML treatments when air exposure was prolonged to $12 \mathrm{~h}$ and $48 \mathrm{~h}$, respectively, and Pichia kudriavzevii was only discovered at $24 \mathrm{~h}$. K. marxianus and $P$. membranifaciens were not isolated after aerobic deterioration occurred. The dominant yeast species in fermented TMR during air exposure are listed in Table 6, and the species Zygosaccharomyces bailii was the only dominant yeast species isolated in all treatments at $30 \mathrm{~d}$.

\section{DISCUSSION}

During the feed-out phase, aerobic deterioration eventually occurs in silages as a result of aerobic microbial activities (Muck et al., 1991). In the initial phase of aerobic deterioration, the easily oxidizable WSC can be quickly depleted, and consequently, the more complex constituents such as CP tend to increase on a DM basis. With the progression of deterioration, complex carbohydrates such as starch are degraded further, and this can lead to increased concentrations of WSC in the later stages of aerobic deterioration (Tabacco et al., 2011). As shown in this study, aerobic deterioration of non-fermented and fermented TMR can lead to high losses of important nutritional components and largely reduce the DM digestibility. Thus, aerobic stability is an important factor influencing the nutritional quality and subsequent feeding value for ruminants (Filya, 2003).

Remarkable decreases in lactic acid concentrations during air exposure can be expected to occur in most silage, primarily because lactic acid can be used as a substrate by some aerobic microorganisms in the presence of air (Ohyama et al., 1975). However, in the non-fermented TMR of this experiment, lactic acid concentrations first increased and then decreased during aerobic deterioration. A similar result was also obtained in a previous study (Wang and

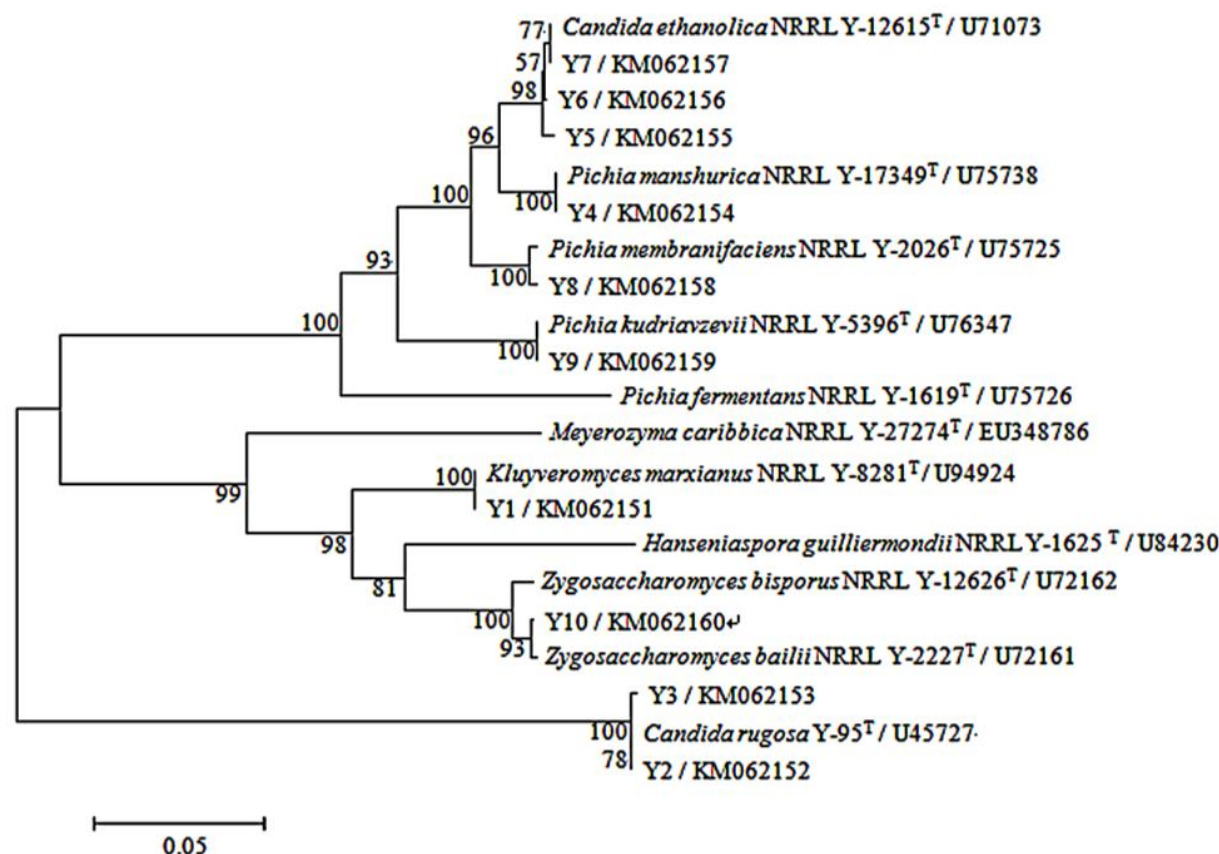

Figure 4. Phylogenetic tree showing the relative positions of isolated yeast strains and related species as inferred by the neighbor-joining method of complete D1/D2 region 26S rDNA gene sequence. Bootstrap values for a total of 1,000 replicates are shown at the nodes of the tree. The bar indicates 5\% sequence divergence. The GenBank accession no. of each type strain D1/D2 region 26S rDNA sequence was shown behind the type strain. 
Nishino, 2008b). This changing trend could be due to the combined activities of lactic acid-assimilative microorganisms and facultative anaerobic LAB. The facultative anaerobic LAB could effectively consume the abundant WSC and produce lactic acid under aerobic conditions, while the lactic acid-utilizing yeasts or other aerobic bacteria could metabolize lactic acid simultaneously. Acetic acid has been found to be one of the most effective substances for the inhibition of spoilage microorganisms. In non-fermented TMR, acetic acid concentrations decreased significantly during deterioration, mainly due to volatilization under aerobic conditions. Although the presence of acetic acid bacteria was not determined in this study, the oxidation of acetic acid by acetic acid bacteria might also occur during the extended phase of aerobic deterioration (Spoelstra et al., 1988).

The microbial processes involved in aerobic deterioration are well established, and yeasts have been widely accepted to be responsible for the onset of silage deterioration. Yeasts can survive at a fairly low $\mathrm{pH}$ and tolerate organic acids better than other aerobic microorganisms under aerobic conditions (Ohyama et al., 1975). Aerobic bacteria also have an important function in silage deterioration (Woolford, 1990). Results from a study conducted by Spoelstra et al. (1988) revealed that acetic acid bacteria could be solely responsible for initiating spoilage in whole-crop maize silage, and Liu et al. (2013) suggested that aerobic bacteria, especially Lysinibacillus fusiformis, could promote deterioration in corn stalk silage. Although corn silage was incorporated into the TMR of this experiment, the initial $\mathrm{pH}$ was approximately 5.2, which may not be low enough to inhibit the activity of aerobic bacteria, implying that the contribution of aerobic bacteria to the deterioration of non-fermented TMR might be equivalent to that of the yeasts. However, when the changes in temperature during air exposure were compared with those of populations of yeasts and aerobic bacteria, yeast growth preceded the significant heating as well as the growth of aerobic bacteria, indicating that yeasts could be responsible for the onset of aerobic deterioration of nonfermented TMR. Non-fermented TMR with a relatively HML was more prone to aerobic spoilage, which can be expected since moister conditions favor the growth of yeasts. An increased rate of yeast growth in the HML treatment was observed, further confirming the influence of moisture level on aerobic spoilage.

In general, the yeasts involved in aerobic deterioration can be classified into two groups: those that can use organic acids, such as Candida and Pichia, and those that can use WSC, such as Torulopsis (Woolford, 1990). The genera Candida and Pichia were frequently observed during aerobic deterioration in this experiment, whereas the genus
Torulopsis was not discovered. Sterilized water was added to produce the different moisture levels of TMR; thus, we can assume that all of the treatment groups were started with the same yeast strains. K. marxianus, C. rugosa, $C$. ethanolica, P. manshurica, and P. membranifaciens were identified in the non-fermented TMR. K. marxianus was previously discovered by denaturing gradient gel electrophoresis analysis in non-fermented and fermented TMR (Wang and Nishino, 2013), and C. ethanolica and $P$. manshurica were also isolated as the prevalent species during deterioration in sugar-cane silages (Carvalho et al., 2014). C. rugosa was reported to be present in high concentrations in TMR samples (Scaccabarozzi et al., 2011), and this yeast species accounted for the majority of the high yeast counts observed during the process of aerobic deterioration in this experiment. It has been reported that $C$. rugosa is able to use lactic acid as a sole carbon source for growth (Dalmau et al., 2000), and this could account for the occurrence of C. rugosa in every phase of aerobic deterioration. C. ethanolica was isolated as a dominant yeast species in non-fermented TMR during the initial phase of aerobic deterioration. The counts of $C$. ethanolica significantly increased to approximately $10^{6}$ to $10^{7} \mathrm{cfu} / \mathrm{g}$ DM around the time that deterioration occurred in each treatment, suggesting that $C$. ethanolica may be closely associated with deterioration in non-fermented TMR. $K$. marxianus and P. membranifaciens were not detected after $12 \mathrm{~h}$ of air exposure, indicating that they likely do not take part in aerobic deterioration. P. manshurica and $P$. kudriavzevii did not dominate the yeast community during deterioration but were sometimes present in considerable numbers. They might not play significant roles in deterioration, although their abilities to utilize lactic acid during aerobic metabolism have been confirmed previously (Carvalho et al., 2014).

Yeast counts can be largely reduced with anaerobic fermentation and fermented TMR exhibits considerable resistance to aerobic deterioration. For the fermented TMR in this study, aerobic deterioration only occurred in the HML treatment after $30 \mathrm{~d}$ of air exposure. The yeast population in the HML treatment dramatically increased to approximately $10^{9} \mathrm{cfu} / \mathrm{g} \mathrm{DM}$ and $Z$. bailii was the sole yeast species isolated when spoilage occurred, indicating that vigorous yeast growth, especially the growth of $Z$. bailii, can trigger deterioration in fermented TMR. Z. bailii is one of the most highly represented spoilage yeast species in food, and it is well known for its high tolerance to low $\mathrm{pH}$ and weak acids. Acetic acid can exhibit antifungal activity, particularly under acidic conditions; however, Z. bailii is known to be capable of growth in a medium with more than $2 \%$ acetic acid (Sousa et al., 1998). This could account for the vigorous growth of $Z$. bailii in the HML treatment of 
fermented TMR in this experiment. The large decrease in acetic acid concentration during air exposure could be due to volatilization as well as the $Z$. bailii utilization. Lactic acid concentration displayed a declining trend in the later phase of air exposure, and this could result from the metabolic effect caused by $Z$. bailii in the presence of air (Carvalho et al., 2014). Although the species Z. bailii also dominated in the LML and MML treatments, the populations were approximately $10^{4} \mathrm{cfu} / \mathrm{g} \mathrm{DM}$ at $30 \mathrm{~d}$ of air exposure. The relatively low counts of $Z$. bailii could account for the higher resistance to aerobic deterioration in the LML and MML treatments of fermented TMR under aerobic conditions.

Aerobic stability is of great importance because deterioration not only causes nutrient and DM losses, but also leads to health risks to animals due to the mycotoxins produced by undesirable microorganisms (Schmidt and Kung, 2010). The results reported in this paper show that a relatively low moisture content of TMR and anaerobic fermentation can neutralize deterioration significantly, and this could potentially lead to the improvement of the preparation, transportation, and fermentation of TMR. This experiment also identified the species of yeast that are associated with aerobic deterioration in non-fermented and fermented TMR. Studying the relation of yeast species to the spoilage process could deepen the understanding of aerobic deterioration, and further research will be conducted to ascertain an appropriate method to inhibit the activities of related yeast species, enhancing the aerobic stability in nonfermented and fermented TMR during their feed-out phases.

\section{CONCLUSION}

Non-fermented TMR when exposed to air deteriorates rapidly, which causes high losses of nutritional components and largely reduces the DM digestibility. A relatively LML enhances the stability of TMR, and fermented TMR exhibits considerable resistance to aerobic deterioration. Yeasts are responsible for the initiation of aerobic deterioration, both in non-fermented and fermented TMR. C. ethanolica is closely associated with the deterioration process in nonfermented TMR. Vigorous growth of $Z$. bailii triggers aerobic deterioration in fermented TMR, even with high concentrations of lactic and acetic acids.

\section{ACKNOWLEDGMENTS}

This work was supported by the National Natural Science Foundation of China (31172240), National Scientific and Technological support projects (2011BAD17B02), and special fund for Agro-scientific Research in the Public Interest (201003023).

\section{REFERENCES}

AOAC. 1990. Official Methods of Analysis. 15th ed. Association of Official Analytical Chemists, Arlington, VA, USA.

Cao, Y., T. Takahashi, and K. Horiguchi. 2009. Effects of addition of food by-products on the fermentation quality of a total mixed ration with whole crop rice and its digestibility, preference, and rumen fermentation in sheep. Anim. Feed Sci. Technol. 151:1-11.

Carvalho, B., C. Ávila, M. G. C. P. Miguel, J. C. Pinto, M. C. Santos, and R. F. Schwan. 2014. Aerobic stability of sugarcane silage inoculated with tropical strains of lactic acid bacteria. Grass Forage Sci. http://dx.doi/10.1111/gfs.12117

Dalmau, E., J. L. Montesinos, M. Lotti, and C. Casas. 2000. Effect of different carbon sources on lipase production by Candida rugosa. Enzyme Microb. Technol. 26:657-663.

Filya, I. 2003. The effect of Lactobacillus buchneri and Lactobacillus plantarum on the fermentation, aerobic stability, and ruminal degradability of low dry matter corn and sorghum silages. J. Dairy Sci. 86:3575-3581.

Kimura, M. and T. Ohta. 1972. On the stochastic model for estimation of mutational distance between homologous proteins. J. Mol. Evol. 2:87-90.

Kurtzman, C. P. and C. J. Robnett. 1998. Identification and phylogeny of ascomycetous yeasts from analysis of nuclear large subunit (26S) ribosomal DNA partial sequences. Antonie van Leeuwenhoek 73:331-371.

Liu, Q. H., T. Shao, and J. G. Zhang. 2013. Determination of aerobic deterioration of corn stalk silage caused by aerobic bacteria. Anim. Feed Sci. Technol. 183:124-131.

Makimura, K., S. Y. Murayama, and H. Yamaguchi. 1994. Detection of a wide range of medically important fungi by the polymerase chain reaction. J. Med. Microbiol. 40:358-364.

McDonald, P., A. R. Henderson, and S. J. E. Heron. 1991. The Biochemistry of Silage. 2nd ed. Chalcombe Publ., Cambrian Prrinters, Ltd., Merlow, Bucks, Aberystwyth, Wales, UK.

Muck, R. E., R. E. Pitt, and R. Y. Leibensperger. 1991. A model of aerobic fungal growth in silage: 1. Microbial characteristics. Grass Forage Sci. 46:283-299.

Nishino, N. and H. Hattori. 2007. Resistance to aerobic deterioration of total mixed ration silage inoculated with and without homofermentative or heterofermentative lactic acid bacteria. J. Sci. Food Agric. 87:2420-2426.

Nishino, N., H. Wada, M. Yoshida, and H. Shiota. 2004. Microbial counts, fermentation products, and aerobic stability of whole crop corn and a total mixed ration ensiled with and without inoculation of Lactobacillus casei or Lactobacillus buchneri. J. Dairy Sci. 87:2563-2570.

Ohyama, Y., S. Masaki, and S. Hara. 1975. Factors influencing aerobic deterioration of silages and changes in chemical composition after opening silos. J. Sci. Food Agric. 26:11371147.

Saitou, N. and M. Nei. 1987. The neighbor-joining method: a new method for reconstructing phylogenetic trees. Mol. Biol. Evol. 4:406-425.

Scaccabarozzi, L., C. Locatelli, G. Pisoni, G. Manarolla, A. Casula, V. Bronzo, and P. Moroni. 2011. Short communication: Epidemiology and genotyping of Candida rugosa strains responsible for persistent intramammary infections in dairy 
cows. J. Dairy Sci. 94:4574-4577.

Schmidt, R. J. and L. Kung Jr.. 2010. The effects of Lactobacillus buchneri with or without a homolactic bacterium on the fermentation and aerobic stability of corn silages made at different locations. J. Dairy Sci. 93:1616-1624.

Sousa, M. J., F. Rodrigues, M. Corte-Real, and C. Leao. 1998. Mechanisms underlying the transport and intracellular metabolism of acetic acid in the presence of glucose in the yeast Zygosaccharomyces bailii. Microbiology 144:665-670.

Spoelstra, S. F., M. G. Courtin, and J. A. C. Van Beers. 1988. Acetic acid bacteria can initiate aerobic deterioration of whole crop maize silage. J. Agric. Sci. 111:127-132.

Tabacco, E., F. Righi, A. Quarantelli, and G. Borreani. 2011. Dry matter and nutritional losses during aerobic deterioration of corn and sorghum silages as influenced by different lactic acid bacteria inocula. J. Dairy Sci. 94:1409-1419.

Thompson, J. D., D. G. Higgins, and T. J. Gibson. 1994. CLUSTAL W: improving the sensitivity of progressive multiple sequence alignment through sequence weighting, position-specific gap penalties and weight matrix choice. Nucl. Acids Res. 22:4673-4680.

Wang, F. and N. Nishino. 2008a. Ensiling of soybean curd residue and wet brewers grains with or without other feeds as a total mixed ration. J. Dairy Sci. 91:2380-2387.

Wang, F. J. and N. Nishino. 2008b. Resistance to aerobic deterioration of total mixed ration silage: Effect of ration formulation, air infiltration and storage period on fermentation characteristics and aerobic stability. J. Sci. Food Agric. 88:133140 .
Wang, C. and N. Nishino. 2013. Effects of storage temperature and ensiling period on fermentation products, aerobic stability and microbial communities of total mixed ration silage. J. Appl. Microbiol. 114:1687-1695.

Weinberg, Z. G., Y. Chen, D. Miron, Y. Raviv, E. Nahim, A. Bloch, E. Yosef, M. Nikbahat, and J. Miron. 2011. Preservation of total mixed rations for dairy cows in bales wrapped with polyethylene stretch film - A commercial scale experiment. Anim. Feed Sci. Technol. 164:125-129.

Woolford, M. K. 1990. The detrimental effects of air on silage. J. Appl. Microbiol. 68:101-116.

Xu, C. C., Y. M. Cai, N. Moriya, and M. Ogawa. 2007a. Nutritive value for ruminants of green tea grounds as a replacement of brewers' grains in totally mixed ration silage. Anim. Feed Sci. Technol. 138:228-238.

Xu, C. C., Y. Cai, J. G. Zhang, and M. Ogawa. 2007b. Fermentation quality and nutritive value of a total mixed ration silage containing coffee grounds at ten or twenty percent of dry matter. J. Anim. Sci. 85:1024-1029.

Xu, C. C., Y. M. Cai, J. Zhang, M. Fukasawa, and N. Moriya. 2008. Ensiling and subsequent ruminal degradation characteristics of barley tea grounds treated with contrasting additives. Anim. Feed Sci. Technol. 141:368-374.

Xu, C., H. Wang, F. Yang, and Z. Yu. 2011. Effect of an inoculant and enzymes on fermentation quality and nutritive value of erect milk vetch (Astragalusadsurgens Pall.) silages. J. Anim. Feed Sci. 20:449-460. 